\title{
Male and female in organizational behavior $^{1}$
}

\author{
LLOYD E. SANDELANDS* \\ Department of Psychology, University of Michigan, U.S.A.
}

\begin{abstract}
Summary The human division of male and female sexes has profound unacknowledged consequences for behavior in organizations. Sex is not simply an individual difference (like eye color), but is an essential part played in life with others. This essay finds sex to be the main organizing principle of human life. Bringing this fact to light, the essay shows how we can begin to understand many perplexing problems of reconciling men and women in organizations today. Copyright (C) 2002 John Wiley \& Sons, Ltd.
\end{abstract}

\section{Introduction}

Sex - the fact we are male and female - ought to be a bigger idea in the study of organizational behavior than it is. Sex is the first thing seen about us at birth, and the main thing we see in ourselves throughout life. Yet, few students of organizational behavior see much significance in sex. Work organizations especially are supposed to be comprised of rational individuals, male or female it does not matter. Perhaps some students give sex short shrift because it rests uneasily with social values for equal opportunity and equal outcomes. Perhaps others lose the meaning of sex in culturally relative talk about gender. And perhaps others still dismiss sex as a neurotically over-simple category for analysing a complex social world (see, e.g., Adler, 1978). But, all the while we are baffled and chagrinned by sex in organizations; mute about its myriad problems of prejudice, harassment, occupational segregation, glass ceilings, and office romance; stumped to explain why it is difficult to live peaceably as a community of equal individuals.

I suppose that we do not see sex as the important factor it is in organizational behavior because we think about it incorrectly as an attribute of individuals - as an individual difference like hair or eye or skin colour. In fact, sex is the opposite of an individual difference. To be male or female is not only to be marked among others, it is also to be related to others. To be male or female is to stand in age-old, and mostly unconscious, relations to others who are male or female. Indeed, to be male or female is the surest affidavit that we are not individual and self-sufficient, but that we take definite and inalienable parts in the life of the species.

* Correspondence to: Lloyd E. Sandelands, Department of Psychology, University of Michigan, 525 East University Avenue, Ann Arbor, MI 48109-1109, U.S.A. E-mail: sandel@bus.umich.edu

${ }^{1}$ This article is based in large part on ideas developed in the author's book Male and Female in Social Life, Transaction Publishers, New Brunswick, Jersey, 2001, and appears here with the permission of the publisher. 
I argue in this essay that contemporary human organizations-be they business corporations, schools, churches, or governments - are underlain by primeval forms of social life rooted in sex (in particular, the mother-child pair, female mate choice, male contest, family, male grouping, and female grouping). Below the surface of the most egalitarian Kibbutz or white shoe investment bank or third world athletic shoe factory run deep sexual currents. Although social, political, economic, and technological complexities obscure the fact, we are social animals concerned mainly to reproduce. Underneath all, we are organized for sex. Bringing this fact to light, we can better understand the many and various sexual perplexities of contemporary organizational behavior.

I make these arguments braced for the reactions they may evoke. Some may ask if these arguments prove only a cultural bias, perhaps seeing in them a certain male-inflected tendency. Others may fault these arguments for resting on sex differences and sex relations that are too pointed and too finely drawn. And still others may dismiss these arguments as 'essentialist' and evidently mistaken in their biological determinism. I will count the essay successful if it challenges these familiar reactions and if it reinvigorates a discussion about sex in organizational behavior.

\section{Dark Matter Mystery}

There can be no envying the student of organizational behavior, for our subject may be the most difficult in all of science. There are many reasons for difficulty, but the main one has to be that the subject is us. How can we understand human nature as it plays out in organizations when understanding itself is part of that human nature? Where do we leave off and where does our subject begin? How can we be 'objective' when we are both the subject and object of study?

Our main difficulty is gaining perspective. As the fish would be last to discover water, we are last to discover the sea of sociality around us. We are tied to others everywhere all the time. Seated before my computer at the university I am wired to legions seated before theirs. Great libraries and databases, records and reflections on all matters human, lie at fingers' beck. Marching my office walls are phalanx upon phalanx of book and journal, invitations all to the thought and feeling of others. A swivel of a chair finds photograph, painting, print, statue, and cartoon - soulful communiques from inner worlds. To my right a desk clock leaps hash mark to hash mark, a reminder of who I am and where I am supposed to be. Next door are parallel societies, the same as mine only completely different. Across the hall, a living breathing secretary aids my commerce with others, via meeting, correspondence, office appointments, telephone, fax, inter-office mail, and preparation of course materials. Floors below dozens of faculty and staff repeat the drill, while hundreds of students take in and challenge all that comes their way. Never mind the newspaper I glided over this morning, the lecture I will give this evening, the signs I will read driving home or the radio that will keep my company along the way. Why is our human (and organizational) life so saturated with others?

Our sociality is doubly impressive for its exquisite design. Human society is all complementarity and reciprocal differences, worked out in thorough detail. The mating pair divides male and female according to physique, psyche, function, and role in a dance of life choreographed in evolutionary time. Family divides husband, wife, and child according to role, rights, and duties. Other groups divide leader and follower, and grade one another in fine shades of status. Work organizations divide functions and distinguish tasks in smallest detail. In Adam Smith's famous example, 18th century pins were made in 18 steps, each performed by different persons linked in a complex interdependence. Somehow these intricate coordinations are brought off - trains run nearly on time, food arrives fresh to market, power and water answer to a switch or knob, new products meet the demands for them; there 
are teachers for students, police for criminals, celebrities for the faceless, and politicians for the voiceless. Needs are filled, questions answered, problems solved. It is a dazzling fittingness. How does it happen?

The intricate coherence of our organized life puzzles because we lack the perspective needed to see into it. And this is because we ourselves are formed by this organized life. We in the West especially take part in an economically and technologically advanced culture that has produced a substantial individuality and a powerful ideology of individualism to support it (Shanahan, 1992). We see social life in terms of the individuals we believe ourselves to be. We look out upon organizations to see a play of individuals in motion and in interaction. A cohesive work group or ball team looks to us like people with strong desires to belong to the group. An extensive authority hierarchy looks to us like a collection of vertical dyad linkages. A powerful leader looks to us like a person in control of rewards, punishments, expertise, or charisma. Communal values such as loyalty and trust look to us like an inducements-contributions contract. It is no surprise then that when it comes to explaining organized life we keep to individuals. We grant individuals organization-forming powers of social concern, attraction, and needs to belong (Baumeister and Leary, 1995). We reduce groups and organizations to selfinterested individuals linked by exchanges ( $c f$. Homans, 1950; March and Simon, 1958; Axelrod, 1984). Our science of economics makes the individual its primary fact, as Arrow (1994, p. 3) notes: 'The individual in the economy or in the society is like the atom in chemistry; whatever happens can be described exhaustively in terms of the individuals involved.' When we come across the powerful coherence of organizational behavior we look out for the 'glue' or atomic force that holds individuals together.

By seeing social life in this atomistic way, we are sure to misapprehend its intricate coherence. As Durkheim (1893/1933) made clear, there is nothing in individual will or activity to account for the whole. To interact at all, people must already want and know how to get along with one another. They must already be socialized members of a civil society. According to Durkheim, when we see social life and organization in terms of individuals we mistakenly assume that what is first in perception (namely, the flesh envelopes and personalities we call individuals) must be first in fact. The truth is the other way around. Our world of interacting individuals is a late development of an already formed and organized social life. Arrow (1994) echoes the point, finding that economic models presuppose an unanalysed social order. The market that enables pricing and exchange is a social institution beyond individual design or choice.

With this puzzle, we in the field of organizational behavior face a mystery similar to that facing astronomy today. Astronomy is baffled by the coherence of the visible universe. Moons gather around planets, planets congregate in solar systems, stars coalesce in galaxies, and galaxies clump in textures that are beyond current astrophysics to explain. The obvious elements of the cosmos (e.g., stars, comets, planets, and moons) do not have enough mass to account for their organization. This unaccounted coherence has led to a fantastic postulate of invisible 'dark matter,' coextensive with visible matter, to explain the universe. Calculations suggest that this as yet undiscovered dark matter may comprise upwards of 90 per cent of the universe - a humbling if not humiliating realization for astronomers. We in organizational behavior are likewise baffled by the coherence of our social lives. We are pressed to explain superfluous grouping and irrational kindness. We wonder why anyone cooperates in a 'prisoners' dilemma', why there is a pervasive value for equity, how rapid trust arises between strangers, why people follow leaders into atrocities, how crowds form and grow, why there is whistle-blowing, volunteerism, and self-sacrificing citizenship, and where courage comes from. The obvious elements of social life - namely, its individual atoms - do not have the qualities or motivations to account for their togetherness, let alone for their intricate patterns. Perhaps there is an analogous dark matter beyond plainly visible persons that can account for our organized behavior. 


\section{What Alien Eyes Might See}

Our organized life is not only or even primarily the multiplicity imagined by social psychologists and economists. More than that, it is a living unity, an organism (cf. Sandelands, 1998). However, to see this we need to look at our social life in a new way - with the new eyes that come of a fresh imagination. In particular, we must let go the prejudices to see social life in terms of individuals. We must let go the tendency to project our own valued individuality into the facts before us. As a start to this end, I suggest a little thought experiment. Imagine how our social life might look to an alien intelligence seeing it for the first time. Looking us over, what would an alien intelligence see?

To begin, let's acknowledge that unless a good deal more intelligent than we, an alien intelligence might also be amazed by the complexity of our social life. Probably it would see few unexcepted principles of order and a greater number of general trends. Almost certainly it would see things we cannot see, or at least things we do not ordinarily see clearly. With a viewpoint unfettered by personal concerns, I imagine this alien intelligence would see more coherence and more organism in our social lives than we do.

First off, an alien intelligence would see that we are a single species made of many members. Where we speak metaphorically and often hopefully of the family of man, an alien intelligence would see this as a literal truth. Probably this intelligence would be less impressed with distinctions of race and ethnicity that matter to many people today and more impressed by the commonality across such distinctions.

Second, an alien intelligence would see that our species is divided into two body plans, corresponding to what we call male and female sexes. These body plans serve complementary functions for the species: one oriented to adventure, group defence, and sexual initiative; the other oriented to mate choice, gestation, nurturing offspring, and making a home. These body plans have different physiology and different needs.

Third, an alien intelligence would see that species members are often grouped in time and space according to body plan (sexes). It would note that young males play together and young females play together-in nursery schools, on playgrounds, in games - and that these groupings are rarely breached. It would note that this pattern continues, albeit with many more exceptions, into adulthood, as older males group in sporting contests, on expeditions, in construction crews, on the battlefield, in business and government organizations, while older females group in schools, nurseries, in community activities and services, in the home. Grouped in such activities, males and females do different things - males competing with each other for status in formal hierarchies, bound by rules and by honour, and engaged in projects that reach outside the home into the larger world; females joined in support networks in domestic tasks of childcare and homemaking. It would note that in addition to forming same sex groups, males and females form pair bonds, of varying intensity and length. The pair bonds often result in sexual intercourse and in some cases yield offspring. Where there are offspring they are almost always attended by adult females.

Fourth, an alien intelligence would see that much of the activity and life of the species is concerned in one way or another with the interplay of the two sexes and with the interplay of the different groupings they define. Much of what males and females do is connected to the interests and activities of the sex-based groups they form. Males and females face different demands from their same sex peers and from their opposite sex partners. Indeed, social life is largely a matter of reconciling the demands of these two kinds of groups.

And finally, being perceptive, our alien intelligence would see crosscurrents that add turbulence to the pattern above. One crosscurrent is homosexual pair bonding. Homosexual males and homosexual females relate in ways that both resemble and differ from heterosexual males and heterosexual females. Yet, even here, where its means and effects are inverted, sex remains an organizing principle. A more important crosscurrent is formation of individual lives to rival the life of the species. Certain 
persons, in certain parts of the world, in certain historical periods, march to their own drummer, according to private imperatives that are beyond the group. Our alien intelligence would perhaps find it remarkable that these individual lives - a late and partial development of a few persons in a few areas of the world - are the main focus of human social science.

If there is a signal lesson to be taken from our alien informant it is this: that human nature is dual. We are not simply individual lives connected by self-interest. We are also parts of a species life defined by and animated by sex. We are each an individual person - a distinctive mind and personality - and we are each part of a living species made of sex defined groups. Nowhere in the animal kingdom are individual and species life so clearly bifurcated. A social insect, for example, knows only the life of the species. An ant does not act alone-it runs errands for the colony, its grocery list written in chemical markers. By comparison, and to the chagrin of parents, teachers, and social planners, we are not so regimented. We also act on our own, on rival directives of personal will.

Langer (1962) introduces the concept of individuation to reckon with this duality. Individuation is the extent to which the life of a species is concentrated in and fulfilled by its members. The life of an unindividuated species is spread out among its members and comes into focus only when considering the species as a group or whole. Langer (1962) gives the example of the honeybee. Its life belongs principally to the colony. The colony forages, the colony builds a nest, and the colony reproduces. The individual bee can do none of these things. It has a place in these activities that depends largely on its sex and size, but it has no say in how or when these activities occur. The beehive, according to Langer, is no conspiracy of cooperating bees. As bees lack the freedom and ability as individuals to behave any other way, they cannot choose to cooperate. In contrast, the life of individuated species, such as our own, is concentrated more fully in its members. To a degree unprecedented in the animal world, we take personal responsibility for the life of the stock. We choose where and how to live and we choose whether and how to cooperate with others.

At the same time, however, we are also an un-individuated species. We cannot reproduce alone. This fundamental business of the species is spread out over two physically distinct organisms, male and female. Thus our individuation is irremediably partial. ${ }^{2}$ Yes, we can decide many things in life for ourselves, about what to do and how to live (more than any other animal by far). But we cannot decide for ourselves to reproduce. We cannot decide to be attracted to the opposite sex and to be oriented (in one degree or another) to procreating and nurturing offspring. As an individual, I can act as I please. But as a heterosexual male I cannot help but be attracted to females, be competitive with other males, or be tender to my children. I can be socialized to resist these impulses. I can even try to sublimate them in myself. But I cannot choose not to have them. When it comes to sex, there truly is a lesson in the birds and the bees.

We are both an individuated animal and an un-individuated animal. With individuation comes the question of how to divide life between self and group. We take part in two lives, distinct and interdependent. We play our part in vital group activities such as reproduction, food gathering, and defence even while we break away to build a life of mind for ourselves. And to the degree we develop the latter we must be socialized to do our duty in the former. Integration of these two lives is rarely perfect - the balance lopsided by too much or too little individuality.

Organizational behavior is puzzling to think about because while it divides along the two tracks of individual and species life, our thinking about it follows one track or the other (indeed, it is

\footnotetext{
${ }^{2}$ With an eye on modern reproductive technologies, such as in vitro fertilization, artificial insemination, and surrogate mothering, it might be objected that it is today possible to reproduce alone and, therefore, that human individuation is today complete. Whether or not this is true, there is less to this objection than meets the eye. Human nature has evolved over time scales of millions of years. Against the pull of this much longer history, the possibilities introduced by modern reproductive technologies, while culturally challenging, are far too recent to have substantially altered human sensibilities and tendencies. Indeed, evolution is the conservative force that defines modern reproductive technologies as controversial.
} 
characteristic of a track of thought that it does not announce or admit alternatives). How easy it is to forget that modern ideas of human nature are just that, modern ideas. We in the field of organizational behavior tend to see the individual as a life apart from the species and, in a breathtaking denial of evolution, assume it has always been this way and could only be this way. We tend not to see that a substantial individual life is a late and contingent development of Western culture. More important, we tend not to see how the bedrock unity of the species makes possible and gives shape to individual life. We do not see how this bedrock unity keeps people working on behalf of the group instead of spinningoff into egocentrism. This bedrock unity, articulated and animated by the species division of male and female, is the 'dark matter' holding our social life together.

\section{A Singular Event in One Long Story}

With the idea that our species is un-individuated in respect to reproduction we come to a difficult truth-namely, that a significant part of our behavior is not individually oriented or individually motivated, but is instead concerned with the life of the species as a whole. Some part, perhaps the greater part, of what we do at work, in the home, in school, and even at church, is concerned with sexual reproduction. And much, perhaps most, of this behavior takes place, as Freud pointed out, without conscious awareness on our part. This truth is difficult because it means that to see ourselves clearly we must see ourselves differently. We must drop the conceit that we are individuals - alike and comparable — and embrace instead the politically dangerous idea that we are male or female parts of a larger species life-unalike and incomparable. Rather than begin analysis with individual interests that compound and combine to form exchange relations and economic organizations, we must begin with a species unity that remains despite differentiation of parts. We must see our human life in something like the way we see a tree. A mature elm tree is a marvel of balance and organization, its unity elaborately differentiated through time. This balance and organization is truly mystifying if we see it from the standpoint of individual leaves. How could so many leaves come together around so many twigs, around so many branches, around such a well-balanced system of limbs, and all in respect to a single trunk? We don't think to explain a tree by its leaves. We know instead that the tree is a story of organic differentiation and growth through time. Why do we think to explain our own species' equally marvellous balance and social organization by its individuals? Isn't it likely that our story, too, is one of organic differentiation and growth through time?

The key to understanding the sexual elements of organizational behavior comes in understanding how the human division of male and female plays out to organize human behavior. To be sure, this is a long and complicated story that I can tell only in barest outline here. It is a story in three 'parts' that I conceive of as interacting moments of social life: (1) division of the sexes; (2) play of the sexes; and (3) organization of the sexes. I speak of these parts separately, but with the reminder that they cannot be separated in fact because each implies and is implied by the others.

\section{Division}

The wisdom in the word 'sex' comes in its being both a noun and a verb. As a noun, sex is a quality that distinguishes one half of the species from its other half. Between male and female are natal differences of body and activity as well as engendered differences of feeling, belief, attitude, and behavior. These differences make an exquisite complementarity. As a verb, sex is an act that unites male and female 
parts in intercourse. To have sex is both to be distinct (as male or female) and to overcome distinction. The word 'sex' wisely pairs division with unity and pairs substance with activity. Sex differences call for sexual relations that reproduce sex differences.

Sex embodies the basic principle that life takes form and energy from division. In living things, division means polarity, tension, and dynamism. To survive, a divided whole must coordinate its parts. Where the whole is parsed and specialized its parts must be integrated. Where once went the solidarity of an unbroken whole now goes the solidarity of interdependent parts. Thus, the organic division of sex brings texture and nuance to species life. Male and female lead different lives with different aims. According to Freud, all social attraction - all that can be subsumed under the heading of love-is born of the complementarities of sex. Sexual desire is an acute attraction. A great many other attractions arise as displacements, projections, or sublimations of intercourse. By dividing the interests and labours of the species between members, sex holds the species together by requiring members to work together to survive. With division of the whole comes adaptation of every part to every other part. Each has its place in the whole.

But why sex? Why a division of species into male and female parts? Biologists explain sex by its effects on the number and diversity of forms. Sexual reproduction recombines genes to produce more varied genotypes - thus enhancing a species' chances of adapting to unsteady or changing circumstances (Williams, 1975). Biologists also explain sex by its role in selecting adapted phenotypes - thus providing the species a mechanism for matching genotypes to circumstances. This is the process of sexual selection described by Darwin whereby females consort preferentially with males they judge most fit.

More important than these explanations for sex, even if less emphasized by biologists, sex promotes adaptive social order. Along with the alien intelligence visited earlier, we find human groups of many kinds based on sex. Females act together-to play dolls or house in childhood, to coordinate oestrous cycles, to bear and nurture children, to manage male sexual interest, and to reinforce male hierarchy. Males act together - to establish a status hierarchy, to muster sexual initiative in the face of frustrations, to venture from the home for resources, and to defend the group against enemies. And these sex groupings interact in varied ways to fit the species to its circumstances. We see this particularly as conditions of life change, as they did for our hominid ancestors some 3-4 million years ago when they left (or were driven from) the safer and more abundant biome of the forest for the more dangerous and hardscrabble biome of the savannah. Tiger (1969), among others, speculates that adaptation to this new life was enabled by a primate sexual organization that linked males in robust status hierarchies around a leader and that linked females in mutual tasks of childcare and mate selection. Males were preadapted to a new life that demanded collective hunting of other animals for food and collective defence of the group against predators. In the millions of years since the move to the savannah, male anatomy, physiology, and psychology evolved to specialize in concerted group activity. Females were likewise pre-adapted to a more complex social and material life that demanded more intensive care of young that needed more time to learn and to grow into adult groups. In the intervening ages, female anatomy, physiology, and psychology evolved to specialize in protracted child rearing and education. Thus a social organization rooted in sex allowed our ancestors to leave the trees for the savannah and set in motion a path of development that culminated in modern Homo sapiens.

Of course, there can be gains in sexual division and social order only so long as the sexes maintain the integrity of the species and particularly its capacity to reproduce. Sexual division comes with problems to solve. One is attraction-divided sexes must seek one another to combine. Another is transportation-divided sexes must surmount distances and barriers. A third is selection-divided sexes must find the best combinations. And a fourth is support-offspring must survive to reproduce. These problems may be best met on the model of two kinds of organisms; one to take primary (but not sole) responsibility for bridging distance and for overcoming boundaries, another to take primary (but not sole) 
responsibility for combining genes intelligently and making fruit of their union. Among mammals, where this model is generic, we call the one male and the other female.

The problems of reproduction (attraction, transportation, selection, and support) appear in virtually every detail of our own human lives-from the dance of sex cells at conception, to the impulses and movements of adult bodies in intercourse, to the folkways of courting and domesticity that underlie pair bonding and family life. In the moments leading to conception millions of sperm race a large distance for a small chance to be incorporated by the egg to fertilize it and set a life in motion. This story in microcosm - of male interest, activity, and contest and female attraction, discernment and nurturing -is paradigmatic. We see its elements in singles bars, on playing fields, in families, in political arenas, in business and commerce, in the arts. Crude but largely correct to say, in body and mind the male is essentially an elaborated sperm - he is designed for contest and courting, moved by hopes of being chosen. Likewise, in body and mind the female is essentially an elaborated egg — she is designed to have and hold, moved by the demand to choose well (Symons, 1979). To see only this much about the sexes is to understand a great deal about the social life they together define. Theirs is a deep history of productive reciprocity that can be traced back millions of years. We may think sex a personal affair, or at most an intimacy of two, but its full measure is the social organization of the species. Sexual desire is not an individual hankering, it is the will of the group. ${ }^{3}$ The social world runs on and is for sex.

\section{Play}

With division of a whole comes a play of parts. And with division of a whole comes life-viva la difference. Perhaps nowhere in nature is this identity of division, play, and life more true and more evident than in the species division of male and female. In light moments we may say that sex makes the world go round, but rarely do we appreciate how near the truth we come. Male and female play with and against each other - the so-called 'battle of the sexes.' Males play with and against other males in contest for females. Females play with and against other females for male attention and support. These world turning dynamics of sex explain much of our organized behavior.

There is a battle of sexes - a play of sexes - to the degree sexes divide the life of the species (i.e., to the degree the species is un-individuated). Where there are clear divisions of responsibility between the sexes-i.e., clear sex roles - there are clear lines between them they must negotiate and cross for the good of the species. Biologists explain sex roles by the demands posterity makes on males and females. Trivers (1972), for example, finds that interest in and care for offspring follows investment in offspring. In almost all species the female puts more into offspring than the male. This is especially and universally true of mammals where the female makes a nutrient-rich egg, harbours a demanding fetus through gestation, undergoes an effortful childbirth, and nurses an infant after parturition; while the male makes millions of sperm daily and takes little time and energy to pass them around. According to Trivers, because the female mammal does not get many chances to conceive, and because each conception demands so much from her, she secures her posterity best by providing for offspring until they can reproduce. In contrast, because there is virtually no limit to the number of chances the male has to conceive and because each conception demands so little from him, he secures his posterity best by minimizing his investments in offspring and by mating as many partners as possible. He does best to 'love 'em and leave 'em', especially when he can rely on his consorts to care for offspring after he's gone.

\footnotetext{
${ }^{3}$ The biology of attraction is, fundamentally, the biology of division. It is not simply that opposites attract, but that elements formerly united and now complementary attract. 'Libido' is the name for the biological force released when organic wholes are divided and parts separated-be it a colony of bees, flock of birds, or human family. This can happen either by physical separations of members from the group, or by differentiation of members from one another so that they no longer relate to each other as before.
} 
While the human battle of the sexes unfolds within this broad mammalian outline, to understand its particulars we must look at how biological investments are shaped by learning and culture. Perhaps the most comprehensive attempt to do this was Margaret Mead's Male and Female, published in 1949. Against the example of Western culture in the United States, Mead contrasts seven South Sea peoples: the Samoans, the Manus of the Admiralty Islands, the mountain Arapesh, the cannibal Mundugumor of the Yuat River, the lake-dwelling Tchambuli, the Iatmul head-hunters of the Great Sepik River, and the Balinese. Mead begins, as we have, with biology, noting:

The differences between the two sexes is one of the important conditions upon which we have built the many varieties of human culture that give human beings dignity and stature. In every known society, mankind has elaborated the biological division of labour into forms often very remotely related to the original biological differences that provided the original clues (p. 7).

The limits on the ways of life, according to Mead, have primarily to do with the structure and function of male and female bodies:

Because we are mammals, and male and female mammals at that, we have limitations, and we must know them, provide for them, keep them safely in our habits, if not continuingly (sic) and boringly in our minds. There are certain things that men cannot do because they are men, and women cannot do because they are women: begetting, conceiving, carrying, bearing, and suckling the next generation are divided differently. As the bodies of the two sexes develop, to be ready for their different roles in reproduction, they have basic needs, some of which are shared, some of which are different even in little children. All through our lives, the fact that we are creatures who are made not only to be individuals, but to continue the human race, is a persistent, unavoidable condition that we must meet (p. 20).

While Mead finds important culture differences in how battles of the sexes play out, she and we find regularities in the battles that we may guess to be universals. Most impressive to Mead is that women assume primary if not exclusive responsibility for the young. She points out that in no civilization do educated and responsible men care for infant young. According to Mead, this regularity of maternal care-which takes different forms between mother and son and between mother and daughter-is the foundation of sexual identity and social destiny.

A second regularity is that men organize into groups headed by a leader. Together in hierarchies men hunt, make war, build, and produce art. Mead shows that men's groups differ in activity, differ in how far they go to exclude women, and differ in how much they swagger. But always they make some part of the world their own in which they can compete and achieve as men, apart from women. According to Mead (p. 160):

In every known human society, the male's need for achievement can be recognized. Men may cook or weave or dress dolls or hunt humming-birds, but if such activities are appropriate occupations of men, then the whole society, men and women alike, votes them as important. When the same occupations are performed by women, they are regarded as less important. In a great number of human societies, men's sureness of their sex role is tied up with their right, or ability, to practice some activity that women are not allowed to practice. Their maleness, in fact, has to be underwritten by preventing women from entering some field or performing some feat. Here may be found the relationship between maleness and pride.

A third regularity is an orientation to the female and to the idea of superior female power. Mead found this orientation in pervasive rituals of male initiation, which she interpreted as compensations for the male's basic inferiority to the female. Writes Mead (p. 103): 
The basic theme of the initiatory cult ... is that women, by virtue of their ability to make children, hold the secrets of life. Men's role is uncertain, undefined, and perhaps unnecessary. By a great effort man has hit upon a method of compensating himself for his basic inferiority. Equipped with various mysterious noise-making instruments, whose potency rests upon their actual forms being unknown to those who hear the sounds-that is, the women and children must never know that they are really bamboo flutes, or hollow logs, or bits of elliptic wood whirled on strings - they can get the male children away from the women, brand them as incomplete, and themselves turn boys into men. Women, it is true, make human beings, but only men can make men. (p. 103)

Others find this same compensatory tendency in our Western culture (e.g., Fox, 1994; Horney, 1967; Paglia, 1990). For example, the psychoanalyst, Horney (1967), reaches this conclusion from her clinical observations of men, who she says are typically persecuted by a fear of being rejected and derided, and which she traces to a mortal dread of woman and woman's power. She asks: 'Is not the tremendous strength in men of the impulse to creative work in every field precisely due to their feeling of playing a relatively small part in the creation of living beings, which constantly impels them to an overcompensation in achievement?' (p. 61) The celebration of male achievement and male values, and corresponding deprecation of female achievement and female values, by both men and women in the West, she believes, reflects an unconscious resentment against women.

Finally, a fourth regularity of the battle of the sexes, connected to the last, is the tremendous power that female mate choices have on male activity. Men play in games for status to impress women. That men often seem to play their games as ends in themselves does not upset the point that their motivations are in mating. High school boys in Texas play football on Friday nights, gangsters in Russia fight authorities for economic control, captains of industry angle in China for market share, brothers in Cairo shout across a backgammon board, sociologists debate fine points of theory in the American Journal of Sociology, subway motormen in New York City race their trains from the 33rd Street Station to 42nd Street Times Square, and fathers in Ann Arbor on a father-daughter canoe trip break into a race as they return to the dock. Although such games may seem remote from the reproductive project, the ballplayer, politico, capitalist, sibling, sociologist, engineer, and father (and we might as well throw in philosopher, impressionist painter, bull-fighter, fisherman, rock star, and construction worker) want the same thing - to impress and win the girl. It is a common mistake to think the many forms of men's play frivolous and not part of the serious business of mating and making a life. Workplace, ball field, and bedroom differ mainly in the weight attached to the game's outcomes. We admit as much when using each as a metaphor for the others. American boys brag of sexual exploits in a baseball vernacular of bases reached and scoring. Barely older boys prate of business exploits in football terms or yet again in sexual terms. A close look at motivations in these instances induces a surprising conclusion about what is serious and what is not. Writes George Bernard Shaw: 'Men trifle with their business and their politics, but never trifle with their games. It brings truth home to them. They cannot pretend that they have won when they have lost, nor that they have made a magnificent drive when they foozled it. The Englishman is at his best on the links and at his worst in the Cabinet.'

All told, while details of the battle of the sexes vary from one society to another, the outline of the battle is universal. Females coalesce to care for children, secure in their place at the centre of species life; males gather in hierarchies to support the group and thereby find meaning for their existence. Females seek the most resourceful and reliable males; males compete in every way possible for access to females. Cultures differ principally in how sharply they draw the lines between the sexes, in how adults and particularly mothers care for children, and in how males cope with being reproductively peripheral. 


\section{Order}

With the play of sex comes the social order of sex. Sexual play and social order relate inseparably as process and structure. Thus far I have spoken of sex as a process visible in the battle between the sexes. At last we can see sex as a structure of social life generally and of organizational behavior particularly. At last we can see how our individual-centred conception of organized life must be qualified by a species-centreed conception of organized life.

For the purposes of this essay, I identify two sexual orders as fundamental in the evolution of our social life. I begin with the sexual order inherited from our mammalian ancestors. I call this the primary or zoological order of human social life. I then turn to a distinctively human sexual order that emerged with migration of our hominid ancestors from the safety of trees to the dangers of open savannah. I call this the secondary or archaeological order of human social life. ${ }^{4}$

I define primary sexual order as that prevailing at the origin of our species. We are clearest about nearest history, about how our social life recapitulates that of our primate and mammal progenitors. From studies of mammals and primates we can identify three elements of primary order in human social life: female care of young, female mate choice, and male competition. These are the most profound elements of social organization - universal, refractory, and conserved by and through millions of years of mammalian and primate evolution. Written into the fibre of our being, these elements unite us with primates and confirm our place on the evolutionary tree. At the same time, and as we shall see, these elements are the bases for specifically human adaptations that distinguish us from other primates and mammals.

Together, the three elements of primary sexual order comprise the central dynamic of social life. This is the dialectic of sexual opposition and affirmation. On the one hand, female care of young, female sexual choosiness, and male competition divide the sexes. The sexes stand opposite one another, each having its own business and orientation to the other. On the other hand, female care of young, female sexual choosiness, and male competition unite the sexes. The sexes affirm one another, each needing the other to complete its biological destiny. This push and pull of sex identifies the primary social order as living form, a dance without end.

I define secondary sexual order as the distinctive human adaptation to Pleistocene life on the African savannah. Lasting millions of years, the Pleistocene period comprises nearly all of our species history, making it the most formative period of our evolution. This is where to look to see how and why we differ from sibling primate and cousin mammal species. For a primate species already divided between male and female, the move from trees to savannah could not but bring further differentiation and specialization of the sexes. Evolution works with and upon differences. For males the move called for closer and more intensive cooperation, partly to defend a species located more vulnerably in open grasslands and partly to hunt for meat and thereby take nutritional advantage of eating higher upon the food chain. This encouraged several mutually reinforcing male adaptations-including an ability to act responsibly in groups; a vocal tract capable of modulated calls and commands in collective action; an ability to imagine and locate objects in space and time; an upright posture to see at a distance and free the hands for uses other than locomotion; a capacity to throw objects accurately over distance; and a larger brain to do all these things. For females, too, the move onto the savannah called for closer and more intensive cooperation, mainly to care and protect young, but also to police and defend female mating prerogatives. This, likewise, led to a number of mutually reinforcing female adaptations - including an ability to read and respond to feelings in others (men and children); again a vocal

\footnotetext{
${ }^{4}$ In Sandelands (2001) I go on to identify higher order sexual elements of social life that appear variably in human cultures (what I call the tertiary or anthropological order of human social life). In Western culture these elements significantly include the individual and bureaucracy. However, for reasons of simplicity and space I refer the interested reader to that other work for details. Leaving these higher order elements aside does not change the argument I am making in this essay.
} 
tract capable of modulated speech; again an upright posture freeing the hands; and again a larger brain to do these things. The move to the savannah led also to a great increase in female attractiveness to males. As males formed tighter groups oriented to greater adventures farther from females and infants, females needed a firmer hold on male attentions to ensure their return with needed provisions. The species responded with two adaptations that heightened female attractiveness to males: continuous sexual availability and cryptic ovulation. Unique among primates, human females do not advertise when they are fertile and they do not limit their sexual availability to fertile periods. This makes females a constant interest to males. With the promise of sexual gratification, males do not stay away long, they hurry home.

The adaptations of male and female to Pleistocene existence produced two distinctively human elements of sexual order. One is same sex grouping: a tendency for men to group with men and for women to group with women. Though characteristic of men and women alike, sex grouping figures differently in the lives of each. Compared to women, men are more resolved to group tasks and group goals and are better able to act in close order. To hunt on the open savannah, Pleistocene men moved together quietly to stalk an animal and then to form a closed circle to mob the animal. To ward off threats of a predator or enemy, Pleistocene men collected their efforts to mount a force more impressive than any one man could muster. This orientation to group tasks and group goals has remained true of men through the ages. Stand before the prehistoric Stonehenge, or the pyramids of ancient Egypt, or the medieval cathedral at Chartres, or the skyscrapers of New York City today and see the singleminded and coordinated muscle of groups of men over the ages. Discount men's bias in the telling and human history is still a tale of men's groups venturing forth to do things: to build, to explore, to conquer, and to know. Sex grouping has different foundations among women. Even before the Pleistocene, women were preoccupied with more personal concerns. Women collaborate to better their reproductive chances in a perilous world, mainly by sharing childcare, food gathering, and homemaking, but also by standing together against unwelcome advances of men. Such collaboration was needed on the Pleistocene savannah where predation was a constant threat, where food sharing was a necessity, and where males left home in groups to hunt. Such collaboration has remained important throughout human history as women continue to rely upon variously reliable men for support. Today, excepting occasional terrorists, dangerous predators have given way to deadbeat dads in an expensive economy. Thus, women come together in a different way and for different reasons than men. They do not collect to coordinate their efforts for a group goal. Instead, they collect to assist one another in central life tasks of finding a mate, bearing children, and caring for children until they mature.

A second element of secondary sexual order to evolve with Pleistocene migration to the savannah is family. Family is the most important grouping to come of the species division into male and femalemost important because it is the reproducing unit of the species. It consists of a woman with children attached more or less exclusively to a man. The woman is almost always the mother of the children, the man is typically, but not always, the father. Sex between the woman and man is usually, but not always, monogamous (or nearly so).

The precursors of family appear in the primary order of mammalian and primate social life described earlier. Among our mammal ancestors the hubbub of hierarchy-obsessed males clamoring to impress choosy females produced only brief impersonal matings - flings with no strings. Females mated the highest-ranking males (in some species the alpha male almost exclusively) and, once pregnant, left the sexual stage to care for the young in the female group. Later, females of certain primate species (including the precursors of modern baboons, chimpanzees, and humans), granted sexual favours also to males who consistently helped them with food and children-males that could be described as 'friends' (Smuts, 1985). And so was inaugurated a sexual economy in which males were sexually rewarded not only for being dominant, but also for being reliably helpful. This development was crucial because it meant that a great many more males could gain access to females. In principle, if 
not in fact, every male could befriend a female and thereby gain mating chances that otherwise belonged to the dominant male.

It is likely that family evolved as a solution to unique problems of savannah life. Family adapted the species to conditions where men in groups left the village to hunt and to explore and women stayed closer to home to gather nearby foods and to care for children. Family promised woman a man to return with food, to defend her and her children from attack, and to help with child-care. Family promised man a woman with whom he could mate and from whom he could receive comfort. She gives him sexual outlet and paternal confidence, he gives her resources to raise children, and both give children a fulsome opportunity to grow and develop under parental care. Since the Pleistocene era, family continues to fit and reinforce the pattern of men in groups leaving home to act on the world and women in groups at home to care for children. Thus, family appeals to woman and man for different reasons. It consoles woman's concerns for resources in a dangerous world where needy children make her vulnerable. And it consoles man's concerns for mating opportunities and paternal certainty in a world where women could be fertile at any time and are always ready for sex. So congenial is family to human existence that we might wonder if it was a consequence of hominid migration onto the savannah or a factor contributing to this migration. With family to stabilize relations between the sexes, hominid females could cooperate in mutual support with minimal concern for who among them would capture the attention and resources of which males; while hominid males could cooperate for mutual gain in group tasks with likewise minimal concern about which of them would mate which females. Family facilitates cooperation within and between sexes (Fisher, 1982).

There are two things to say in review of the two elements of secondary sexual order, same sex groups and family. First, we do best to think of these two elements as we think of the three elements of primary social order, as parts of one species life. Again, these elements comprise a dialectic of opposition and affirmation. In the most robust men's or women's groups there is a hint of family, and likewise in the warmest and cosiest domestic scene there is a brooding presence of single sex groups. One enters a men's or women's group in part to leave family behind and in part to prepare for a return. Men learn to compete fairly with other men so as to be attractive to women. Women learn to make wise choices and to care for young so as to be attractive to men. By the same token, one seeks a family life in part to leave the men's or women's group behind and in part to set the stage for a return. In the family, men and women learn how the other feels, thinks, and acts. However, while love of mate and love of children make man and woman whole, this comes at the risk of losing one's sexual identity, which must be reclaimed in the same sex group.

Second, the two elements of secondary sexual order, same sex groups and family, are inextricably tied to the three elements of the primary sexual order described earlier (that is, female care of young, female mate choice, male competition). Sex groups begin in the battle of the sexes. Men face the mammalian imperative to show themselves in contests so that females can select mates for the good of the species. As men conspire to compete before discerning women, they enact a reproductive scheme that is tens of millions of years old. They do not choose this; they do this because they are mammal and male. What distinguishes men's groups from male groups of other species is the reach of their competitive impulse, which goes far beyond plonking contests of brute strength or hunting prowess. Watch men in groups build a spaceship or a social science and see two of the farther reaches of male competition. For their part, women face the mammalian imperatives to select mates wisely and to nurture young; imperatives that are acute among highly sexed and strongly altricial primates. As women collect to defend their sexual prerogatives and to care for young, they too recap an age-old reproductive scheme. Like the men, they do not choose this; they do this because they are mammal and female. What distinguishes women's groups from female groups of other species is again the reach of these reproductive impulses, which go beyond choosing mates and rearing children. Watch women defend the defenceless, fight for the oppressed, nurse the sick, or support others in modern corporations, and 
see three of the farther reaches of these aboriginal urges. Humans are mammals like every other, only more so.

The family also begins in the primary social order, and particularly in the mating games played between the sexes. Where sex groups recapitulate the separate male and female parts of the primary sexual order, family reconciles those parts. Family balances man's concerns about sex (his interest to mate as widely as possible, his anxieties about paternity) with woman's concerns about sex (her interest to find the best genes, her anxieties to find a mate she can count on). The two agree in the family. Man trades a possibility of promiscuous mating for a sure partner and a guarantee of paternity. Woman trades interest in the most impressive man for a lesser but more reliable partner. Family integrates women's concerns within the group for child and home with men's concerns outside the group for hunt and defence. As women mind the children, men worry the group's relations to the wider world. And, family marries women's and men's different concerns for organization-hers for supportive personal relationships, his for hierarchy and group goals. It is more than a stereotype that women think personally about family relationships and that men think formally about those same relationships. She notices and worries that the children are not getting along, or that romance has left the marriage. He thinks the family an organization of rights and duties, with himself the leader and his wife and children the subordinates.

Thus the secondary sexual order presupposes the primary sexual order. To be human is not only to stand apart from other animals in uniqueness; it is also to stand with other animals in an evolutionary continuity. Same sex groups and family are distinctively human elements of social life, but they could not exist apart from mammalian elements of female care of young, female mate choice, and male competition. The battle of the sexes that separates male and female groups puts them into opposition. The mating game that unites male and female in a reproductive mission gives them reason to work through this opposition. Thus in primary sexual order we find the original values for human fraternity and for human sorority and the original values for the human family. Design a social life without one of the primary elements of order - without women caring for children, or without women choosing mates wisely, or without men competing for women's attention and favour-and you design a social life without sex groups and without family. These contingencies imply continuity and stability. As a new social order is built upon old social orders, it cannot depart from them too dramatically without undermining itself. Thus, while we can imagine all kinds of social orders, we expect to find only those that accord with the biological secondary and primary sexual orders whence they came. These contingencies thus imply conservation of social order compatible with reproduction of the species.

\section{Perplexities No More}

The field of organizational behavior is sometimes focused on behavior in organizations, sometimes focused on behavior of organizations, and sometimes focused on behavior that $i s$ organization (Heath and Sitkin, 2001), but always it is focused on behavior that is human. And for this primary fact, the field is always and ineluctably about two different and incommensurate lives - that of the individual and that of the species.

Thus the student of organizational behavior faces the difficult truth that human behavior does not arise and reside solely in individual life, but in large (and perhaps larger) measure it arises and resides in species life. As we've seen, this truth rears its ugly head particularly in considerations of sex -in the fact we are not simply individuals, but a species divided between male and female. Sex matters in organizational behavior in ways that defy and perplex our individual centered conceptions of behavior. 
To illustrate the problem, let me take as an example an exemplary research report on the subject of gender differences at the bargaining table by Kray et al. (2001). The report aims to explain the wellestablished finding that in bilateral negotiations men are more competitive and reap better personal outcomes than women. The report begins by assuming that this finding is not the result of innate difference but instead is the result of traditional ideas about the sexes (called gender stereotypes) that are imposed on individuals by others. The report supposes further that gender stereotypes work implicitly. In the authors' words (p. 943): 'We hypothesize that men and women perceive a correlation, or mapping, between negotiator stereotypes and classic gender stereotypes. Evidence that modern sexism is subtle and covert ... leads us to believe that this mapping process is not necessarily explicit, but rather implicit.' Accordingly, if women underperform men in negotiations it is not because women are less able or less motivated, but because women are subtly undermined by gender stereotypes while men are subtly bolstered by gender stereotypes. The report finds that the usual male-female difference in bargaining outcomes appears when subjects are told that outcomes are a measure of ability and when subjects are told that successful outcomes reflect masculine traits of rationality, assertiveness, and self-interest. The report finds no male-female difference in bargaining outcomes when subjects are expressly told that men are expected to outperform women. The authors interpret these results as indicating that gender stereotypes affect bargaining outcomes silently and non-consciously. Furthermore, when gender stereotypes are brought into the daylight of awareness they lose power because expectations for success fluster men and because expectations for failure provoke women to prove them wrong.

The problem in this report is that it gives no consideration to a much simpler rival hypothesis that derives from the fact we are a species divided between male and female. This is that men outperform women at the bargaining table because men, as males, are innately more concerned than women, as females, to prove themselves in contests. On this hypothesis we would expect that when success and status are explicitly linked to bargaining outcomes (as they are in this report), males work harder and more determinedly than females to achieve better outcomes. On this hypothesis there is no need to invoke the social machinery of stereotypes and the cognitive machinery of implicit (non-conscious) priming and self-fulfilling expectations to explain sex differences in bargaining outcomes. All that is needed is to see that male and female play different parts in social life and that these parts destine them to different interests, behaviors, and interpersonal relations. That the male-female difference in bargaining outcomes disappears when gender stereotypes are called to mind suggests that these stereotypes could not be responsible for the difference. Instead, as the authors suggest, these stereotypes may confound men and women who, with the authors, expect there to be no sex differences in a world of equal individuals. The important point is not whether or not this rival hypothesis is superior (though I believe it is), but that it is never considered. There is a need to see sex differences more clearly and fully, not only from the standpoint of individual lives, but also from the standpoint of a species life of male and female division, play, and order.

I believe the example of sex at the bargaining table is emblematic. Sex in organizations perplexes us because we, like the authors above, do not fully grasp the meaning of sex in a world that we suppose is made up of individuals. To borrow a phrase from popular culture, we 'just don't get it' why:

- Men rise higher than women in the ranks of virtually every business, government, and profession. Men are over-represented in executive suites and corporate boardrooms, in national offices of government, on the bench of the judiciary, at the dais of Nobel Prize ceremonies, in military honours, in museums and art galleries, and in the world's finest kitchens. Men are even over-represented at the highest reaches of professions dominated by women - such as social work and nursing.

- Many women report that their contributions in the workplace are not fairly recognized by men. Some report feeling almost invisible. Some women report they are blocked from advancement by a 'glass ceiling' that tempts them with prized positions they cannot win. 
- Women's careers are more adversely affected by family demands than men's careers. Responsibilities of childcare weigh more heavily on them. Women are more likely than men to take parental leave from a job and more likely to quit a job after childbirth.

- Concerns about sexual relations in the workplace have led many government, business, and university organizations to formulate policies against sexual harassment, hostile work environments, and even consensual romances. These policies are a continuing a source of friction in workplaces.

- U.S. courts favour women over men in disputes about child custody. Other things being equal, a woman is more likely than a man to win custody of a child as a result of separation or divorce. Likewise, reproductive rights favour women over men. Whereas a woman has a right to choose whether or not to have a baby, her sexual partner does not.

- Despite clamour from the U.S. Congress, powerful elements of the U.S. military establishment continue to deny women the opportunity to serve the country in combat operations. There is a 'glass ceiling' at the very gates of the military.

- Fundamentalist religions - be these Islamic, Christian, Judaic, or otherwise-distinguish women's and men's spheres of activity in society. They reserve for women the duties of home and childcare and for men the responsibilities of family breadwinning and group defence.

If this essay has been successful, we can now see that these perplexities are of our own making. We are perplexed because we see organizational behavior as an expression of individual lives rather than as an expression of a species life. We are perplexed because we do not see that sex-the fact that we are male or female-is not an individual difference (a feature of a person like height, intelligence, eye colour, or skin pigmentation), but a primary feature and dynamic of an incompletely individuated species. In a word, our problem is a philosophical one of seeing. We look upon organizational behavior and see only the behavior of separate and potentially equal persons acting in self-interest. We do not see the behavior an integral living whole, the behavior of a species life moved by an internal dialectical division of male and female. We do not see that sex is the 'dark matter' that holds our social lives together.

We do not see, as our hypothetical alien a few pages back could see, that human behavior is divided between the distinct claims of an individual life and a species life. Yet, everywhere we look-in every family, church, community service club, military service, business firm, or nation state - we find both lives. Even the most modern, individualistic, and anti-sexist business corporation harbours the sexual elements of species life (a species life of male and female that knows nothing of individuals). This is not hypocrisy, for it could not be otherwise. There will always be conflicts between the rival claims of individual life and species life. Although equally individual, men and women will always self-segregate into groups (e.g., occupations, work roles, support networks) to claim their familiar and preferred fraternity and sorority. Although equally individual, men will always outrank women in status hierarchies, not because men are more talented, but because status is biologically more important to men than women. And although equally individual, women will always feel more of a career-slowing tug toward children and home, not because women don't care about work organizations, but because childcare is biologically more important to women than to men. In this light we see that 'fundamentalist' religions are aptly named because they honour certain fundamentals of human existence connected with sex. Men and women do have different parts to play in the life of the species. Our justifiably prized individual life, with its cherished values for individual liberty and justice, is a late, partial, and contingent development of a much older social life based on the species division of male and female.

At the end of the day, the conflict between the two sides of our human nature is the one truth we can count on. While the progressively minded may see in this a continuing injustice and reason for action, the conservatively minded may see an affirmation of an ageless humanity welcome in its own right. For 
the student of organizational behavior, the challenge is to not let the taking of sides (which perhaps cannot be helped) interfere with the greater responsibility to come to terms with the fullness of human nature.

\section{Acknowledgements}

I would like to thank $J O B$ editor, Denise Rousseau, for her encouragement and most helpful comments.

\section{Author biography}

Lloyd E. Sandelands teaches psychology and business administration at the University of Michigan. His research focuses on the feelings and forms of social life. He is the author of two recent books: Feeling and Form in Social Life (1998, Rowman \& Littlefield); and Male and Female in Social Life (2001, Transaction Publishers).

\section{References}

Adler A. 1978. Cooperation Between the Sexes. Transcated by Ansbacher HL, Ansbacher RR. Anchor Books: Garden City, NY.

Arrow K. 1994. Methodological individualism and social knowledge. American Economic Association Papers and Proceedings May: 1-9.

Axelrod R. 1984. The Evolution of Cooperation. Basic Books: NewYork.

Baumeister R, Leary MR. 1995. The need to belong: desire for interpersonal attachments as a fundamental human motive. Psychological Bulletin 117: 497-529.

Durkheim E. 1893/1933. The Division of Labor in Society. Transcated by Simpson G. Macmillan: New York.

Fisher HE. 1982. The Sex Contract: The Evolution of Human Behavior. Morrow: New York.

Fox R. 1994. The Challenge of Anthropology. Transaction Press: New Brunswick, NJ.

Heath C, Sitkin SB. 2001. Big-B versus Big-O: what is organizational about organizational behavior? Journal of Organizational Behavior 22: 43-58.

Homans GC. 1950. The Human Group. Harcourt, Brace \& World: New York.

Horney K. 1967. Feminine Psychology. Norton: New York.

Kray LJ, Thompson L, Galinsky A. 2001. Battle of the sexes: gender stereotype confirmation and reactance in negotiations. Journal of Personality and Social Psychology 80: 942-958.

Langer S. 1962. Philosophical Sketches. Johns Hopkins: Baltimore, MD.

March JG, Simon HA. 1958. Organizations. Wiley: New York.

Mead M. 1949. Male and Female. Morrow: New York.

Paglia C. 1990. Sexual Personae. Yale: New Haven, CT.

Sandelands LE. 1998. Feeling and Form in Social Life. Rowman \& Littlefield: Lanham, MD.

Sandelands LE. 2001. Male and Female in Social Life. Transaction Press: New Brunswick, NJ.

Shanahan D. 1992. Toward a Geneaology of Individualism. University of Massachusetts: Amherst, MA.

Smuts B. 1985. Sex and Friendship in Baboons. Aldine de Gruyter: New York.

Symons D. 1979. The Evolution of Human Sexuality. Oxford: New York.

Tiger L. 1969. Men in Groups. Free Press: New York.

Trivers RL. 1972. Parental investment and sexual selection. In Sexual Selection and the Descent of Man, Campbell B (ed.). Aldine de Gruyter: New York; 136-179.

Williams GC. 1975. Sex and Evolution. Princeton: Princeton, NJ. 